\title{
La acción popular y el desmonte de su perfil preventivo y correctivo a favor de la corrupción con la derogatoria del artículo 40 de la ley 472 de 1998
}

\section{Popular action and remove your profile preventive corrective corruption in favor of the repeal of article $\mathbf{4 0}$ of law $\mathbf{4 7 2}$ of 1998}

\author{
Mauricio José Álvarez Tafur ${ }^{1}$
}

Recibido: 13-09-2011 Aceptado: 27-10-2011

\section{RESUMEN}

La Acción Popular como una herramienta de control preventivo y correctivo a la administración pública en Colombia, ha sufrido un menoscabo importante en materia de protección de los derechos colectivos a la moralidad administrativa y el patrimonio público, debido a la derogatoria del artículo 40 de la ley 472 de 1998, vía ley 1425 de 2010, reforma que suprimió el incentivo que se establecía por el juez administrativo por un monto del $15 \%$ del dinero recuperado en eventos de corrupción administrativa y en los cuales la participación del actor popular había sido clave. Los objetivos de este escrito reflexivo es ofrecer en primer lugar una visión de los efectos nocivos que se han derivado por la derogatoria reseñada del incentivo económico y de la responsabilidad patrimonial solidaria entre el contratista y servidor público que concurrían en la práctica inmoral, y en segundo lugar realizar una valoración de cómo ha debido abordarse la reforma a la ley 472

\footnotetext{
1 Abogado Universidad Surcolombiana. Especialista en Derecho Contractual de la Universidad del Rosario. Ex coordinador del Semillero de Investigación Facta Nom Verba. 2006. Abogado consultor CICAmauriciojosealvarez@hotmail.com. Bogotá D.C.
} 
de 1998 frente al tema del incentivo que se reconocía en el artículo 40 de ley 472 de 1998.

\section{PALABRAS CLAVE}

Acción Popular, Moralidad Administrativa, Patrimonio Público, Justiciabilidad, Corrupción, Contratación Estatal.

\section{ABSTRACT}

The class action as a tool for preventive and corrective control of public administration in Colombia, has suffered a significant impairment in the protection of collective rights to administrative morality and public property due to the repeal of Article 40 of Law 472 1998, through Act 1425 of 2010, which removed the incentive reform that established by the administrative judge for an amount of $10 \%$ of money recovered in the event of administrative corruption and where the popular actor's participation was key. The objectives of this discussion paper is to provide a first view of the adverse effects that have resulted in the repeal outlined the economic incentive and equity joint responsibility between the contractor and public official who attended the immoral practice, and Secondly make a retrospective assessment of what must addressed the reform of the law 472 of 1998 compared to the incentive issue was recognized in the article of the law 472 of 1998.

\section{KEYWORDS}

Class Action, Morality Management, Public Property, Justice, Corruption, Government Contracts. 


\section{INTRODUCCIÓN}

La derogación por iniciativa del Presidente Juan Manuel Santos con la aprobación del Congreso de la República del artículo 40 de la ley 472 de 1998 por vía de la ley 1425 de 2010, desmontó legislativamente el perfil preventivo y correctivo de la Acción Popular cuando se ejercía como control de legalidad frente a prácticas corruptas en la contratación pública, convirtiendo a esta acción de origen constitucional y de acceso universal por parte de la ciudadanía, en un instrumento deficiente para poder tomar medidas preventivas como resarcitorias en la recuperación de los recursos públicos afectados por sobrecostos (entendido como los mayores gastos e inversiones que tuvo que soportar el contratista en la ejecución del objeto contratado, que no fueron previstos ni reconocidos por la entidad estatal, sin embargo, para los efectos contemplados en la ley 472 de 1998, la acepción de tal término es otra, por cuanto tiene que ver con el valor contratado celebrado, teniendo en cuenta los precios reales del mercado, que en cumplimiento del deber legal impuesto, ha debido ser analizados por la administración de manera previa a la iniciación del proceso de selección y contratación u otras irregularidades como las siguientes. 1. El fraccionamiento de contratos, para eludir el proceso licitatorio y utilizar la excepción de la contratación directa. 2. Comprometer recursos públicos con destinación específica y privilegiada a un objeto distinto. 3 La subcontratación, que ocurre cuando por negligencia o complicidad de los interventores se consiente que el contratista no desarrolle el objeto contractual, si no que lo hagan terceros, en detrimento de la calidad de la obra, 4.Cuando se desconocen imperativos legales y jurisprudenciales a nivel constitucional que prohíben desarrollar cierto objeto contractual por resultar este ilícito.

En síntesis, el común denominador de las irregularidades es la violación a los principios de la contratación estatal y el desvío de poder; presentes en la 
contratación estatal, dejando completamente indefensa la protección oportuna de la moralidad administrativa (Villamizar Shiller, 2006) y el propio manejo del patrimonio público, entendido como los recursos presupuestales del Estado que se destinan para atender las necesidades y derechos sociales de la población, violando por lo tanto los artículos 2, 88 y 209 superiores y desconociendo jurisprudencia de la misma Corte Constitucional. Paso a justificar lo anterior.

\section{El regresivo desmonte legislativo}

El derogado artículo 40 de ley 472 de 1998 exponía lo siguiente:

ARTÍ́CULO 40. En las acciones populares que se generen en la violación del derecho colectivo a la moralidad administrativa, el demandante o demandantes tendrán derecho a recibir el quince por ciento (15\%) del valor que recupere la entidad pública en razón a la acción popular.

Para los fines de este artículo y cuando se trate de sobrecostos o de otras irregularidades provenientes de la contratación, responderá patrimonialmente el representante legal del respectivo organismo o entidad contratante y contratista, en forma solidaria con quienes concurran al hecho, hasta la recuperación total de lo pagado en exceso.

Para hacer viable esta acción, en materia probatoria los ciudadanos tendrán derecho a solicitar y obtener se les expida copia auténtica de los documentos referidos a la contratación, en cualquier momento. No habrá reserva sobre tales documentos.

Para empezar el segundo párrafo del mencionado artículo se configuraba como la herramienta primordial y única que tenía el Juez administrativo de la Acción Popular en el auto de medidas cautelares o la sentencia, para tomar las medidas oportunas frente los sobrecostos, la contratación indebida, pagos de anticipos sin 
garantías, u otras irregularidades acreditadas e igualmente conocidas por vía del proceso de Acción Popular pudieran ser contrarrestadas, decretando con ello medidas preventivas como correctivas que afectaran el patrimonio de los responsables en la defraudación de los recursos públicos y evitar con ello que se insolventaran, (evento que nunca es descartable) pues con fundamento de la disposición legal que consagraba la responsabilidad patrimonial solidaria entre el representante legal de la entidad vinculada en una práctica de inmoralidad administrativa y el contratista o terceros que concurrían en ella, era que se podían tomar estas medidas cautelares y resarcitorias en búsqueda de restablecer una violación a la moralidad administrativa y al patrimonio público, derechos colectivos de rango constitucional según lo establece el artículo 88 de la Constitución Política.

Art. 88 C.P. La ley regulará las acciones populares para la protección de los derechos e intereses colectivos, relacionados con el patrimonio, el espacio, la seguridad y la salubridad públicos, la moral administrativa, el ambiente, la libre competencia económica y otros de similar naturaleza que se definen en ella.

También regulará las acciones originadas en los daños ocasionados a un número plural de personas, sin perjuicio de las correspondientes acciones particulares.

Así mismo, definirá los casos de responsabilidad civil objetiva por el daño inferido a los derechos e intereses colectivos.

Es así que la moralidad administrativa y el patrimonio público como derechos colectivos con rango constitucional perdieron su protección preferencial por vía de la Acción Popular al derogarse la responsabilidad patrimonial solidaria (artículo 40 parte segunda ) entre los responsables del detrimento y menoscabo de los recursos del Estado, dicha responsabilidad solidaria no se podrá predicar en adelante en la sentencia, pues la solidaridad es solo aplicable por consagración 
legal o contractual y en el caso legal, en ninguna otra parte de ley 472 de 1998 se menciona referencia alguna sobre ella.

Por tal motivo el Juez-Administrativo de la Acción Popular se queda sin herramientas para proteger una violación al interés colectivo que se ha reflejado en la pérdida de cuantiosas sumas de dinero, desencadenando con ello la pérdida de la credibilidad institucional por parte de la ciudadanía en el control del interés general y la progresiva desconfianza por el menoscabo a las herramientas constitucionales que desempeñan correctivos en el manejo de la contratación estatal, pues por vía de la Acción Popular tal como quedo hoy en día, nada se puede conseguir en aras de restablecer las cosas a su estado anterior, cercenando la vocación de eficacia de la acción que por preferencia constitucional se destinó para la protección de los derechos colectivos reseñados.

Al respecto, Daza Quintero (2009) expone: "Colombia ha avanzado en los últimos diez años en materia de aprobación de leyes tendientes a evitar defraudar el erario público, posiblemente porque a raíz de la promulgación de la Constitución Política de 1991, los ciudadanos comenzaron a percibir con mayor nivel de conciencia, los estragos que produce la corrupción administrativa, en materia no solo de estancamiento y hasta retroceso social, sino también el desgreño administrativo, que desmotiva la participación política y la falta de confianza en sus instituciones"

\section{La desprotección de la moralidad administrativa artículo 209 y 88 constitucional.}

La derogatoria del artículo 40 de la ley 472 de 1998 también desconoce el artículo 209 de la Constitución Política, éste consagra que la función administrativa está al servicio de los intereses generales y se desarrolla con fundamento en los principios de igualdad, moralidad, eficacia, economía, celeridad, imparcialidad y publicidad, mediante la descentralización, la delegación y la desconcentración de funciones; se reseña entonces que la función administrativa buscará guiarse por la 
moralidad, la cual debe ser protegida preferencialmente por la acción destinada para ello, que es la Acción Popular, artículo 88 Constitución Política, lo cual no podrá acontecer en adelante, pues el único artículo de la ley 472 de 1998 que se dedicaba a establecer medidas para su protección fue derogado, impidiendo su protección integral y eficaz, conclusión que se refuerza con lo establecido por la Corte Constitucional en sentencia C/459/04, magistrado ponente Jaime Araujo Rentería .

En este punto la Sala no encuentra acertada la demanda del actor, y al revés, encuentra legítima la finalidad perseguida que es preservar la moralidad de la función administrativa, consagrada en el artículo 209 de la Constitución. La distinción que se hace por el legislador es razonable ya que por esa vía se refuerza la protección al bien jurídico de la moralidad pública y el recto manejo de la administración pública y en consecuencia la diferenciación se encuentra constitucionalmente justificada.

"Consecuentemente, la Sala encuentra ajustado a la Constitución el artículo 40 de la ley 472 de 1998".

\section{Las contradicciones del ejecutivo y el legislativo frente a su lucha contra la corrupción}

Por parte del Ejecutivo y Legislador colombiano se han presentando argumentos para desmontar el incentivo como estrategia para impedir el abuso en la presentación de acciones populares y con ello detener el pago de los incentivos por parte de los entes territoriales, pero estos argumentos fueron para el caso del artículo 40 de ley 472 de 1998 justificados bajo presupuestos errados e inconstitucionales, pues el incentivo para el caso de la defraudación o detrimento a recursos públicos, no era el Estado víctima quien debía pagar el incentivo, éste se tasaba de acuerdo al $15 \%$ de valor de los recursos que se recuperaran total o parcialmente y que saldrían del peculio privado previamente decomisado, 
secuestrado o embargado de las cuentas, bienes o activos del representante legal de la entidad pública y del contratista como de terceros que concurren en la práctica inmoral administrativa, procedimiento avalado por jurisprudencia de la misma Corte Constitucional Colombiana, en sentencia C/459/04, magistrado ponente Jaime Araujo Rentería.

La Corte se pregunta ahora: ¿quién debe pagar el monto del incentivo decretado por el juez de la acción popular, tanto el del artículo 39, como del 40 de la ley 472 de 1998, sin lugar a dudas este monto debe pagarlo la persona que atentó o vulneró el correspondiente derecho o interés colectivo, pues, no sería lógico ni jurídico que en la perspectiva de proteger derechos e intereses vinculados al cumplimiento de las tareas estatales, sea el mismo Estado quien deba soportar una erogación con ocasión de un proceso en el que se demostró la responsabilidad de un tercero. Es apenas obvio que cada cual debe responder por los efectos nocivos de su propia conducta, lo cual, a más de ser justo y necesario, resulta ampliamente pedagógico en la esfera de las políticas preventivas del Estado sobre derechos e intereses colectivos. Por consiguiente, el monto total del incentivo determinado por el juez debe pagarlo la persona que atentó o vulneró el correspondiente derecho o interés colectivo. Lo que a su vez guarda consonancia con lo afirmado por esta Corporación en sentencia C-088 de 2000.

En el evento del artículo 40, siendo el Estado el afectado o "victima" del acto que afecta la moral administrativa, no puede además ser afectado con una disminución de lo que recupere, siendo lo razonable que el incentivo lo pague el autor o cómplice del detrimento patrimonial. Esta es la misma posición que en la interpretación y aplicación de esta norma ha hecho el Honorable Consejo de Estado y que la Corte Constitucional ahora avala, como manifestación del denominado derecho viviente". (Cursiva fuera del original) 
El anterior pronunciamiento desafortunadamente no fue tenido en cuenta por el Ejecutivo y menos por el Congreso en sus motivaciones de la reforma, un dinero que estaba perdido y que se había logrado recuperar, sería el monto base para fijar el incentivo como premio al ciudadano que con diligencia y experticia había probado la ocurrencia de hechos reprochables en la contratación pública.

Es así que el gobierno con el fin de desmontar a toda costa la presentación de acciones populares y el reconocimiento de las dos clases de incentivos económicos (artículo 39 y 40), no valoró el tratamiento diferente que le debía dar al incentivo consagrado en el artículo 40, al estar éste orientado a acabar con las constantes defraudaciones al erario público, lo que no ocurre con el incentivo del artículo 39, el cual presentaba un abuso progresivo de los actores populares que interponían múltiples acciones sobre un idéntico hecho, con el sólo objeto de recibir una prestación económica; la solución a esta evidente irregularidad resultó siendo contraproducente a los fines de contar con una acción constitucional eficaz en la preservación de la moralidad administrativa.

Una contradicción adicional se presenta con el programa de recompensas que el Ejecutivo en cabeza del Ministerio de Defensa ha implementado para quienes cumplan con su deber de denunciar a los delincuentes, (narcotraficantesterroristas-secuestradores) y lo presenta como la bandera de su lucha contra el crimen organizado; frente a esto el gobierno encuentra que esas recompensas son admisibles, así comprometan grandes sumas de dinero público a favor de los particulares que colaboren con la justicia, pero predica que los incentivos que por vía de la Acción Popular se reconocían después de recuperar dineros públicos que se daban perdidos por culpa de la corrupción, son ilegítimos, algo totalmente contradictorio, pues quienes defienden por vía de la Acción Popular el interés general que es menoscabado por servidores públicos corruptos en complicidad con mafias que deterioran la confianza en las instituciones; están también combatiendo un tipo de crimen organizado, que permea la administración 
pública, y se fortalece cuando los controles tanto cívicos como institucionales presentan baja capacidad de acción, así como, un relajamiento progresivo.

Los actores populares cuando ejercen la función de control cívico de la administración del erario público, también están cumpliendo una función garante del orden democrático y de preservación de las instituciones, las que se ven amenazadas constantemente por el cáncer de la corrupción administrativa, función que se les debe recompensar, pero en el caso en comento, con activos de origen privado tal como lo afirmó Corte Constitucional en sentencia C/459/04, magistrado ponente Jaime Araujo Rentería . "siendo el Estado el afectado o "victima" del acto que afecta la moral administrativa, no puede además ser afectado con una disminución de lo que recupere, siendo lo razonable que el incentivo lo pague el autor o cómplice del detrimento patrimonial".

Teníamos entonces que si el culpable o culpables del evento inmoral que se había reflejado en la pérdida de sumas de dinero de naturaleza pública, era el contratista y el representante legal de la entidad, el patrimonio a perseguir para reconocer el incentivo y recuperar el dinero mal administrado era el de estos sujetos y el de los terceros que concurrían en el hecho, evento que al ser derogado evidencia contundentemente el retroceso que frente a la lucha contra la corrupción se ha configurado.

\section{La violación a los artículos 2 y 88 constitucional}

Al ser derogado el párrafo final del artículo 40 de ley 472 de 1998 se desconoció el artículo 2 y 88 de la Constitución Política pues contradice el deber constitucional de garantizar la efectividad de los principios, derechos y deberes consagrados en la Constitución, con la mencionada derogatoria se desmonta de manera directa la vocación de eficacia que tiene la Acción Popular como medio preferencial para prevenir una amenaza o resarcir una violación de la moralidad 
administrativa y el patrimonio público frente a la mala administración de los recursos involucrados en contratos objeto de control público.

La vocación de efectividad es una característica primordial de la Acción Popular al configurarse como la herramienta que permite prevenir y corregir en temprana oportunidad las irregularidades que estén acreditadas en el sumario, o que generen la certeza de un daño inminente, situación que no acontece con la acción de responsabilidad fiscal, vía procesal establecida para contrarrestar el menoscabo al patrimonio público presente en la gestión fiscal, efectividad que tampoco se presenta frente a la acción de repetición, ya que su finalidad de moralizar la administración pública se dirige especialmente a recuperar la sumas de dinero pagadas por el Estado, por concepto de indemnizaciones derivadas del daño antijurídico consagrado en el artículo 90 Constitucional, herramienta que demanda para su impulso la lesión a un bien jurídico individual imputable a la culpa grave o dolosa del agente público.

La Acción de Responsabilidad Fiscal es primordialmente de naturaleza resarcitoria, de ejercicio posterior y selectivo al evento irregular, lo que no se compadece con la naturaleza preventiva del daño contingente de la Acción Popular, y finalmente la Acción de Responsabilidad Fiscal es de impulso institucional; modelo de control de la gestión fiscal que se inserta dentro del sistema de frenos y contrapesos a la administración pública, evento que no está bajo la misma orientación del acceso universal de la Acción Popular, lo cual le permite lograr garantizar la mayor participación de la comunidad en la protección de los derechos colectivos en mención, los que de manera permanente se encuentran amenazados o violados cuando la corrupción que se apodera de las instituciones públicas en complicidad de mafias de contratistas como de servidores públicos inescrupulosos.

Finalmente la derogatoria del artículo 40 de la ley 472 de 1998 vía ley 1425 de 2010, desconoce el mandato constitucional consignado en el artículo 88 que 
dispone: "La ley regulará las acciones populares para la protección de los derechos e intereses colectivos, relacionados con el patrimonio, el espacio, la seguridad y la salubridad públicos, la moral administrativa, el ambiente, la libre competencia económica y otros de similar naturaleza que se definen en ella".

Se puede colegir de éste artículo que existe un derrotero constitucional sobre la correcta regulación legislativa de la Acción Popular, la cual deberá estar guiada siempre por la búsqueda de la protección de los derechos e intereses colectivos, esto se traduce en unos márgenes obligatorios para tener en cuenta por parte del legislador a la hora de regular esta acción pública de origen constitucional, condición que impide una discrecionalidad absoluta de la competencia legislativa del Congreso; en tal sentido si alguna reforma se presenta en el Congreso frente a la Acción Popular, esta debe coincidir con la preservación de la vocación de eficacia en la protección de los derechos colectivos, con lo cual se garantice una protección plena, pero con la ley 1425 de 2010 la protección de la moralidad administrativa y el patrimonio público han quedado en un estado de incertidumbre evidente, debido a que nada se logra con su declaración de violación o amenaza en sentencia, si el restablecimiento al estado de cosas anterior no es posible actualmente, configurando a la sentencia como un mero acto simbólico sin ninguna trascendencia jurídica, en ese orden de ideas el legislador Colombiano ha desbordado su competencia de regulación, al limitar y restringir la eficacia directa de la Acción Popular en base a principios infra constitucionales no reconocibles explícita o implícitamente en el texto Constitucional (congestión judicial y abuso de la acción) facultad reguladora que tiene sus límites desde el mismo artículo 88 Constitucional y ha desembocado una reforma lesiva al interés general como a la protección de los derechos a la moralidad administrativa y el patrimonio público.

\section{CONCLUSIONES}


El Gobierno nacional identificó un abuso en la presentación de acciones populares ante la jurisdicción contenciosa administrativa, evidenciándose que un mismo actor popular interponía en diferentes lugares sobre hechos similares múltiples acciones, buscando únicamente un incentivo prestacional, frente a ello se promovió una reforma legislativa con el fin de desmontar el reconocimiento de las dos clases de incentivos económicos, artículos 39 y 40 ley 472 de 1998, pero sin detenerse a observar las diferencias teleológicas que orientaban a cada uno, en especial los fines que perseguía la responsabilidad patrimonial solidaridad entre los responsables de actos de defraudación en la contratación estatal, evento consignado en el derogado articulo 40 .

Nos encontramos entonces que debido al abordaje no diferenciado por parte del Gobierno y el Congreso del fenómeno del abuso de la Acción Popular motivada especialmente por el incentivo del artículo 39, y por un confuso entendimiento del origen privado de los recursos con lo que se reconocía el incentivo económico del $15 \%$ se desmontó con la reforma un innovador control cívico con vocación eficacia y acceso universal frente a la gestión contractual pública, acción que edificaba un concepto de derecho moral y racionalmente justificado, que estaba siendo orientado desde una "pretensión de corrección" (Alexy, 2005), búsqueda de una condición ideal de la administración pública pero, finalmente el desmonte vía derogatoria del artículo 40 de ley 472 de 1998, ha desembocado en la pérdida contundente de la justiciabilidad de los derechos colectivos a la moralidad administrativa y el patrimonio público en los eventos de un daño contingente o consumado, exigiendo en adelante el acudir al régimen de la responsabilidad fiscal, ( ley 610 de 2000) que es principalmente de control posterior, en el evento de concurrir el funcionario público y contratista en la práctica corrupta, o a las pólizas de seguros cuando el contratista por ejemplo, incurre en una indebida destinación de los anticipos, alternativas necesarias de tener en cuenta para recuperar los dineros comprometidos por corrupción en la administración de 
recursos públicos, y donde están involucrados el representante legal de una entidad administrativa como los contratistas privados.

Toda esta situación desmejora indudablemente la condición de la Acción Popular como mecanismo preferencial y principal en la protección de los derechos colectivos y desemboca finalmente en un escenario de impunidad favorable a los intereses corruptos de quienes suelen estar involucrados en la contratación estatal, situación de ninguna forma presentable frente a la actual captura del Estado por mafias de contratistas y con la complicidad de funcionarios públicos inescrupulosos.

\section{REFERENCIAS BIBLIOGRÁFICAS}

Alexy, R. (2005). La Pretensión de Corrección del Derecho. Serie Teoría Jurídica y Filosofía del Derecho. Bogotá D.C: Universidad Externado de Colombia.

Amaya Olaya, U. A. (2002). Teoría de la Responsabilidad Fiscal. Bogotá D.C: Universidad Externado de Colombia.

Arango Rivadeneira, R. (2005). El Concepto de Derechos Sociales Fundamentales. Bogotá D.C: Legis.

Colombia, Consejo de Estado Sección Tercera, (2005) "sentencia AP-01195-01"

M. P. Saavedra Becerra, R., Bogotá.

Colombia, Corte Constitucional Colombiana, (2004) "sentencia C-459), M. P. Araujo Rentería, J., Bogotá

Daza Quintero, D. M. (2009). (Tesis Maestría) Alcances de las Acciones Populares que Protegen la Moralidad Administrativa en el caso de la Contratación Estatal. Bogotá D.C: Universidad del Rosario.

Garcia Villegas, M. R. (2010). Estado alterrado,clientelismo, mafias y debilidad institucional en Colombia. Bogotá D.C: Dejusticia . 
Londoño Toro, B. (2007). Justiciabilidad de los Derechos Colectivos. Balance de la ley de Acciones Populares y de Grupo (ley 472 de 1998). Bogotá D.C: Universidad del Rosario.

Perez Salas, D. O. (2007). La Acción Popular frente a los Contratos de la Administración Pública. Neiva: Universidad Surcolombiana.

Presidencia de la República. (11 de Septiembre de 2010). www.presidencia.gov.co. Recuperado el 24 de Septiembre de 2011, de www.presidencia.gov.co:

http://wsp.presidencia.gov.co/Prensa/2010/Septiembre/Paginas/20100911_06aspx

Santos Ballesteros, J. (2002). Instituciones de Responsabilidad Civil. Tomo II. Bogotá D.C: Pontificia Universidad Javeriana.

Villamizar Shiller, E. A. (2006). El Derecho Colectivo " Moralidad Administrativa" en la Contratación Estatal . Revista Estudios Socio Jurídicos , 8 (002), 173-205. 